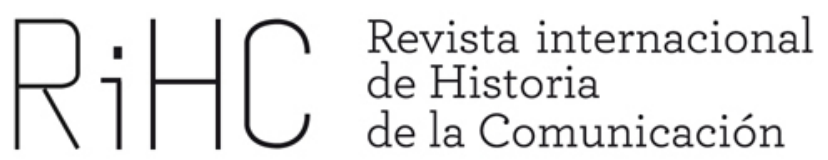

\title{
APORTACIONS BIBLIOGRÀFIQUES A LA HISTÒRIA DE LA PREMSA I DEL PERIODISME A CATALUNYA (2000-2010)
}

DOI: http://dx.doi.org/10.12795/RiHC.2014.i03.08

Josep M. Figueres

Universitat Autònoma de Barcelona

JosepMaria.Figueres@uab.cat

Resum: Visió de conjunt de la bibliografia produïda a Catalunya a la dècada 2000-2010 sobre història de la premsa i del periodisme amb especial èmfasi en l'apartat dels estudis sobre autors i publicacions així com els censos hemerogràfics $i$ els estudis monogràfics tant de conjunt com específics. L'autor s'acosta a la producció bibliogràfica ordenant-la i presentant-la sense valoracions interpretratives.

Paraules clau: Periodisme català, Bibliografia, hemerografia, Estudis història premsa

Resumen: Visión de conjunto de la bibliografía editada en Cataluña, en la década 20002010 sobre historia de la prensa y del periodismo con especial enfasi en los estudios sobre autores y revistas y censos hemerográficos y los estudis monográficos tanto de conjunto como específicos. El autor se acerca a la producción bibliográfica ordenándola y presentándola sin valoraciones interpretrativas. 
Palabras clave: Periodismo catalán, Bibliografía, hemerografia, Estudios historia prensa

\section{Objectiu}

Presentar la bibliografia recent més interessant d'història de la premsa i del periodisme del present decenni a Catalunya publicada per autors catalans i no catalans, sobre aquesta disciplina. Disposem de referències anteriors ${ }^{1}$. Presentem la bibliografia classificada en estudis sobre capçaleres (estudis, censos), autors ${ }^{2}$ (memòries, biografies $\mathrm{i}$ estudis), $\mathrm{i}$ els textos $\mathrm{i}$ fonts (obres completes, facsímils de publicacions) amb la finalitat que permetin elaborar un balanç de les àrees cobertes $i$ de les possibles investigacions a desenvolupar.

\section{Metodologia}

Ens hem basat en la bibliografía acadèmica accessible des del catàleg universitari de Catalunya a (www.cbuc.cat) eina molt valuosa a internet i amb constant actualització a partir de la presència en biblioteques, ho hem acarat, quan ha calgut, amb la bibliografia d'Indice Històrico Español on collaborem en la nostra especialitat d'història de la premsa catalana. El treball l'ordenem sota criteris operatius en quatre grans apartats temàtics:

1.- Censos i estudis de caràcter local i comarcal

2.- Autors: memòria, obra pròpia i estudis

3.- Estudis sobre diaris i revistes

\footnotetext{
1Jaume Guillamet: «Estat de la investigació en història de la premsa i del periodisme a Catalunya. Consultable al web de la UPF dins Aula de periodisme i consultable a http://www.upf.edu/depeca/auladb/pdf/guillamet.pdf (vist el 9-XI-2010) i que ens estalvia de considerar el període anterior al present segle. Guillamet es fixa en el total de referències, de Pella $i$ Forgas (1879) fins a treballs del 2002. Aquesta aportació és essencial, al costat dels articles apareguts a Anàlisi on es glossa la recerca hemerogràfica al País València, Illes Balears i Catalunya.

${ }^{2}$ Només d'autors catalans, tot i la qualitat i la llengua en autors foranis com Robert Fisk: La gran guerra per la civilització. La conquesta de l'Orient Mitjà (Barcelona: RBA-La Magrana, 2006).
} 


\section{4.- Altres estudis}

No incloem capítols d'obres ni tampoc les parts en obres més genèriques d'àmbit superior al català ${ }^{3}$ o superior tot i la presència sovint de dades interessants ${ }^{4}$. Ens fixem en l'àmbit geogràfic de Catalunya i en el d'autors també d'aquesta zona. Si bé els facsímils els recollim no ho fem amb les edicions digitals ${ }^{5}$ ni tampoc les publicacions penjades a webs on es recullen integres ${ }^{6}$ fora de les populars RACO, XAC i ARCA que ofereixen premsa acadèmica viva, premsa local i comarcal i premsa barcelonina en una molt notable eina de gran interès per l'especialista o pel simple curiós.

Partim de dos treballs anteriors nostres. El primer «Fonts documentals per a l'estudi de la premsa catalana» sobre el conjunt de la bibliografia que ordenarem i presentarem a Tripodos, 1 (Barcelona, URL, 1996) i que intenta aplegar tota la bibliografia específicafins el moment de la seva aparició. El segon, dedicat a la bibliografia sobre premsa a la UAB el presentarem a l'Aula del Diari de Barcleona (Barcelona, UPF), amb el títol «Las producció bibliogràfica d'història de la premsa a la UAB. Dades per a un informe historiogràfic (1992-2003) i aparegué a Treballs de Comunicació, núm. 18 (desembre 2003). Amb aquests antecedents ens hem cenyit a presentar la bibliografia apareguda en format llibre, descartant l'especialitzada tot i que n'hem recollit quan apareix en una obra també unitària sobre història de la premsa.

\section{La recerca el període $\mathbf{2 0 0 0 - 2 0 1 0}$}

A «Estat de la investigació en història de la premsa i del periodisme a Catalunya» Jaume Guillamet afirma:

El periodisme català disposa d'una tradició investigadora intensa i variada, però manca encara d'una explicació global i completa del seu procés històric i de

\footnotetext{
${ }^{3}$ Per exemple els treballs d'Antonio Checa Godoy: El ejercicio de la libertad. La prensa española en el Sexenio Revolucionario (1868-1874) (Madrid: Biblioteca Nueva, 2006) o La prensa española durante la guerra de la Independencia (1808-1814) (Madrid: Quorum editores, 2009).

${ }^{4} J a u m e$ Guillamet: Història del periodisme: notícies, periodistes i mitjans de comunicació, (Bellaterra (Cerdanyola del Vallès): Universitat Autònoma de Barcelona, 2003), Aldea global; 14.

${ }^{5}$ Revista Cambrils [Recurs electrònic]: 50 anys pàgina a pàgina guió i direcció: Marcel Blàzquez Mañé Cambrils: Revista Cambrils, 2006, 1 disc òptic (DVD) (57 min.): col. (PAL). Conté: Documental (Evolució de Revista Cambrils i el seu compromís amb la informació local) - 13 galeries fotogràfiques (extretes de l'arxiu fotogràfic de la publicació). També: L'Om, revista de Riudoms [Recurs electrònic]: Any Gaudí 2002 [Riudoms]: Om, 1 disc òptic (CD-ROM), 2003.

${ }^{6}$ Convindria disposar d'un únic gran portal d'informació on es pogués accedir a les capçaleres històriques digitalitzades que la iniciativa privada o altres entitats han posat en línia.
} 
treballs importants sobre les principals publicacions i els periodistes i editors més destacats. L'atenció principal dels investigadors s'ha dirigit, fins fa dues dècades, a la documentació i interpretació dels problemes específics dels periòdics en llengua catalana i del seu desigual desenvolupament històric. Les aportacions més destacades s'han produït en moments d'auge del catalanisme cultural $\mathrm{i}$ polític com el del darrer quart del segle XIX i primer terç del segle XX interromput per la guerra civil de 1936-39- i el nou cicle iniciat a partir de la segona meitat dels 60 , amb una continuïtat expansiva a través dels anys de la transició democràtica, de la Constitució i de l'Estat de les Autonomies.

En altres paraules, la tradició catalana en història del periodisme ha estat molt important, fins i tot s'han estudiat les capçaleres, diàries o periòdiques, i els esdeveniments amb una priorització per les fetes en llengua catalana com veurem. S'ha produït una distorsió considerable, tenim tesis dels primers periòdics però estudis exhaustius dels més destacats en influència, com pugui ser El Diluvio, La Veu de Catalunya o La Publicitat o en tiratge com la mateixa La Vanguardia. Coneixem més de periodistes i de la seva obra, de capçaleres i de tribunes així com de les capçaleres existents. El catàleg de tesi doctorals -www.tdx.cat- ofereix una notable sèrie de autors. Si posem l'entrada periodisme i relacionades amb història trobem pel període que ens ocupa pocs autors, en altres paraules sembla que hi ha poc interès en l'elaboració de tesis doctorals en aquest àmbit específic ${ }^{7}$ quan trobem gairebé dos centenars de tesis per altres aspectes genèrics de la comunicació.

\footnotetext{
${ }^{7}$ Entre altres: Sergi Dòria (2000): La voluntat cosmopolita: Imatges, setmanari gràfic d'actualitats, Barcelona, 1930, (UAB, 2000); Joan Carreras i Pera: Ideari i poètica de Josep Maria Capdevila (UAB, 2001); Carles Castro: La reconversión tecnológica y empresarial en un periódico consolidado: el caso de La Vanguardia (UAB, 2002); Montserrat Satorre, Benjamí: Jaume Collell i Bancells. Perfil biogràfic d'un activista catòlic del catalanisme (UPF, 2002); José M. Perceval: "Opinión pública y publicidad (siglo XVII): nacimiento de los espacios de comunicación pública en torno a las bodas reales de 1615 entre Borbones y Habsburgo», (UAB, 2003); Josep Camps i Arbós: Ramon Xuriguera (1901-1966): ideologia, activitat cultural $i$ literatura (UAB, 2004); Pere Gómez: Quinze anys de periodisme: les colllaboracions de J. V. Foix a La Publicitat (1922-1936) (UAB, 2005); Núria Simelio: Prensa de información general durante la transición política española (1974-1984): pervivencias y cambios en la representación de las relaciones sociales (UAB, 2006); Maria Soledad Vargas: Estilos de vida, ética y estética en los dominicales de los diarios ABC, La Vanguardia y El País (1974-1999) (UAB, 2006); Enric Xicoy: Interpretació periodística del conflicte basc (Avui, El Periódico i La Vanguardia. Setembre 1998 - abril 2000) (URL, 2008); Francesc Salgado: La construcció de la identitat periodística de Manuel Vázquez Montalbán: de la censura a la transició (1960-1978) (UPF, 2009); Àngel Rodríguez: La comunicació catòlica a la diòcesi de Girona. Passat i present (UAB, 2009); Marcel Mauri: Funció i evolució de la premsa de Barcelona durant la transició democràtica (1975-1978) (UPF, 2010).
} 


\subsection{Censos i estudis de caràcter local i comarcal}

Ens trobem amb desigualts materials editats i el primer que cal constatar és la varietat de models. Des d'estudis que inclouen un cens fins a censos o repertoris hemerogràfics estrictes o treballs mitxes que contenen dades dades sense ser un cens. Hem aplegat tots els títols que contenen informació sobre publicacions i així les consignem. En una perspectiva geogràfica ens fixem en censos de Barcelona i en trobem de premsa de barris en treballs sobre la premsa de barris per Maristany i Musons ${ }^{8}$, Guaita i Insa ${ }^{9}$ en la d'uns anys de la Restauració ${ }^{10}$, la musical ${ }^{11}$, la mèdica i la farmaceutica ${ }^{12}$, la castellera $^{13}$, visions actuals ${ }^{14}$ del fenòmen de la premsa local i comarcal de tanta importància en la comunicació catalana contemporània.

Sobre la premsa política i amb el lideratge del CEDOC, dirigit per Eugeni Giral al si de la $\mathrm{UAB}$, trobem censos de la premsa trotsquista ${ }^{15}$, socialista ${ }^{16}$ i d'ERC $^{17}$. La de l'exili ha

\footnotetext{
${ }^{8}$ Gerard Maristany i Albert Musons: Del desencant a la contrainformació: la premsa de barris a Barcelona, 1976-2001, (Barcelona: Diputació de Barcelona: Col-legi de Periodistes de Catalunya, 2002); Albert Musons i Agell: Cens de premsa local de la ciutat de Barcelona (Barcelona: Col-legi de Periodistes de Catalunya, 2000).

${ }^{9}$ Pere Guaita Jiménez i Yolanda Insa Sauras: Publicacions, articulistes i editors a Sant Andreu de Palomar (1868-1938), (Sant Andreu del Palomar -Barcelona-, Centre d'Estudis Ignasi Iglésias, 2006).

${ }^{10}$ Josep M. Figueres: «Les publicacions periòdiques a Catalunya en el moment del Diari Català (1879-1881): cens i estudi estadístic: premsa comarcal» Barcelona: Institut d'Estudis Catalans, 2006), p. 111-139, Butlletí de la Societat Catalana d'Estudis Històrics, 17.

${ }^{11}$ Claudi Fuster i Sobrepere: Catàleg de la premsa musical barcelonina des dels seus orígens fins el final de la Guerra Civil (1817-1939), [Barcelona]: Arxiu Municipal de Barcelona.
}

${ }^{12}$ Alfons Zarzoso i Sara Fajula Colom: Premsa mèdica catalana, (Barcelona: Col-legi Oficial de Metges de Barcelona, 2009) i Premsa farmacèutica corporativa catalana, (Barcelona: Societat d'Amics de la Història i de la Ciència Farmacèutica Catalana, 2003.

${ }^{13}$ Guillermo Soler García de Oteyza: El periodisme casteller: un cas d'identitat, Tarragona: Arola, 2004).

${ }^{14}$ La premsa comarcal: actes i debats del 25è aniversari de l'Associació Catalana de la Premsa Comarcal (1981-2006) [coordinació de continguts: Pere Font], [Barcelona]: Generalitat de Catalunya, Departament de la Presidència, Dir. Gral. de Difusió Corporativa, 2007).

${ }^{15}$ Rafael Iniesta de Manresa: La premsa trotskista (1939-2000). Catàleg de les publicacions periodiques troskistes a les biblioteques catalanes. (Bellaterra: UAB, 2003)).

${ }^{16}$ Eugeni Giral: Les publicacions periòdiques del Partit dels Socialistes de Catalunya (PSCPSOE), Juliol de 1978 - Desembre de 2007 [Recurs electrònic] (Bellaterra: Cedoc-UAB, 2008), 1 disc òptic (CD-ROM).

${ }^{17} \mathrm{~A}$ Gaceta, 2 (2010) revista digital de l'IEC en el número monogràfic que aplega el col·loqui $\mathrm{La}$ premsa d'Esquerra Republicana de Catalunya, 1931-1975 hi ha dos treballs sobre el cens de les revistes d'ERC: "Per un catàleg de les publicacions periòdiques d'ERC» per Eugeni Giral, Xavier Ginesta i Antoni Estupiña i «Catàleg de la premsa històrica d'ERC i entitats adherides (1931-1939)» per Natàlia Lara i Otalora. 
estat, amb la clandestina objecte de diversos repertoris generals de centres ${ }^{18}$ i de caràcter general ${ }^{19}$ o censos específics a cura de Robert Surroca ${ }^{20}$ i Teresa Llorens ${ }^{21}$.

De caràcter general voldríem arrancar amb l'inventari de Josep Faulí sobre la premsa en català ${ }^{22}$. S'han estudiat les primeres publicacions a cura d'Hettinghausen ${ }^{23} i$ Guillamet $^{24}$ i les de la Restauració per Figueres ${ }^{25}$ i Sànchez Cervelló ${ }^{26}$. En un àmbit local disposem de repertoris i estudis específics amb dades de les publicacions i visions de conjunt del periodisme de les següents ciutats i comarques o estats: Sabadell ${ }^{27}$,

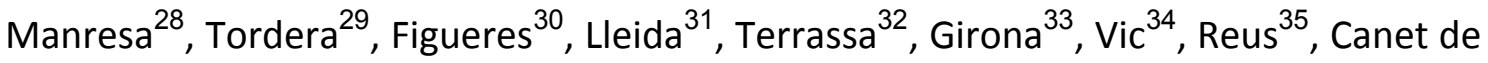

${ }^{18}$ Premsa de l'exili català i republicà: 1936-1975: catàleg del Fons del CEHI al Pavelló de la República, (Barcelona: Centre d'Estudis Històrics Internacionals: Universitat de Barcelona: Fundació Ramon Trias Fargas, 2002); Javier Tébar Hurtado, Juanma García Simal (coords.); La premsa silenciada: clandestinitat, exili i contrainformació: (1939-1977) [Sergi Draper... ], ([Barcelona]: Fundació Cipriano García-Arxiu Històric CONC: CCOO, 2003); Instruments de I'arxiu; 1; Catàleg de publicacions sindicals clandestines a Catalunya [Recurs electrònic]: 19391975 [coordinador investigador: Rafael Iniesta de Manresa; investigador: Daniel Escribano], Barcelona: CESL, [2006], 1 disc òptic (DVD-ROM); Inclou els fons digitalitzats de publicacions sindicals clandestines de l'Hemeroteca General de la UAB, de I'Arxiu Històric de la Ciutat de Barcelona i de la Biblioteca Pública Arús; Javier Tébar Hurtado, Juanma García Simal (coords.).

${ }^{19}$ Josep M. Figueres: Aproximació a la primera premsa d'exili (1936-1952), a L'Exili català del 1936-1939. Un balanç. (Girona: Cercle d'Estudis Històrics i Socials, 2003), p. 211-226.

${ }^{20}$ Robert Surroca i Tallaferro, Prensa catalana en México: (1906-1982), Jalisco: El Colegio de Jalisco i, especialment: Premsa catalana de l'exili i de l'emigració (1861-1976), (Barcelona: Generalitat de Catalunya, Departament de Governació i Administracions Públiques, 2004).

${ }^{21}$ Teresa Llorens Sala: Premsa clandestina i de l'exili a l'Hemeroteca de l'Arxiu Històric de la Ciutat, (1939-1977), (Barcelona: Arxiu Municipal de Barcelona, 2000).

${ }^{22}$ Josep Faulí: Repertori d'una recuperació (aportació): premsa en català 1939-1976 (Barcelona: Abadia de Montserrat, 2006).

${ }^{23}$ Henry Ettinghausen: Notícies del segle XVII: la premsa a Barcelona entre 1612 i 1628, (Barcelona: Arxiu Municipal de Barcelona: Ajuntament de Barcelona, 2000), Textos i documents (Arxiu Municipal de Barcelona); També en format sintètic: Barcelona, un centre mediàtic abans del 1714, (Barcelona: Institut de Cultura, 2009).

${ }^{24}$ Jaume Guillamet: Els orígens de la premsa a Catalunya: catàleg de periòdics antics (16411833), (Barcelona: Arxiu Municipal de Barcelona, 2003).

${ }^{25}$ Josep M. Figueres: «Les publicacions periòdiques a Catalunya en el moment del Diari Català (1879-1881): cens i estudi estadístic: premsa barcelonina», (Barcelona: Institut d'Estudis Catalans, 2007), p. 109-156: Butlletí de la Societat Catalana d'Estudis Històrics, 18, (2007).

${ }^{26}$ Josep Sánchez i Cervelló i Ma. Cinta Margalef: Els límits a la llibertat de premsa a les Terres de l'Ebre durant la Restauració: (1875-1923), (Tortosa: Cooperativa Gràfica Dertosense, 2003).

${ }^{27}$ Gisela Figueras i Cifuentes: Inventari de I'hemeroteca local: publicacions periòdiques sabadellenques (1854-2004); pròleg: Maria del Tura Molas i Alberich, (Sabadell: Arxiu Històric de Sabadell, 2006).

${ }^{28}$ Rosa Maria Vila i Gangolells i Jordi Torner i Planell: Catàleg de la premsa manresana: 18081939, (Manresa: Arxiu Comarcal del Bages, 2008), Inventaris i catàlegs de l'Arxiu; 11.

${ }^{29} \mathrm{M}$. Mercè Torrellas: Tordera en la primerenca premsa comarcal i local, (Tordera: Ajuntament de Tordera, 2009).

${ }^{30}$ Jaume Guillamet Lloveras et al. [et al.]...: Història de la premsa de Figueres: 1809-1980 (Figueres: Ajuntament de Figueres i Diputació de Girona, 2009) i del mateix autor: «Llengua i 
Mar $^{36}$, Baix Empordà ${ }^{37}$, Andorra ${ }^{38}$. De caràcter genèric hi ha censos oficials ${ }^{39}$ tot i que la presència d'organitzacions que aplega els mitjans, diaris, revistes comarcals, premsa gratuïta, etc. fomenta la presència de repertoris digitals amb finalitats informatives, publicitàries i va desplaçant els repertoris escrits...

ideologia a la premsa de Figueres (1939-1974)», Annals de I'Institut d'Estudis Empordanesos, 36 (Figueres, 2003). p. 299-320 i de Manuel Moreno Chacón: «La premsa republicana figuerenca durant la Restauració: 1875-1923», Annals de I'Institut d'Estudis Empordanesos, 34, (Figueres, 2001), p. 427-458.

${ }^{31}$ Arxiu Municipal de Lleida. Hemeroteca Publicacions periòdiques de Lleida (1854-2001): catàleg de l'Hemeroteca de l'Arxiu Municipal de Lleida, (Lleida: Pagès: Ajuntament de Lleida, 2003). La col-lecció «Retalls» d'història del periodisme de l'editorial Pagès, dirigida per Ramon Badia, és una poderosa eina pel coneixement de la premsa lleidatana i de questions de caràcter general. Així citem: Llengua i mitjans de comunicació, Congrés de Llengua i Mitjans de Comunicació (1999), (2000); Xavier Díez: Utopia sexual a la premsa anarquista de Catalunya: la revista Ética-Iniciales, 1927-1937 (2001); Francesc Closa Salinas: Catalanisme i renovació a la premsa carlina a Lleida: ideologia i poder a El Almogávar leridano, El Loredan i L'Almogáver: 1890-1910, (2002); Antonio Jiménez Hijazo: La Revolució Russa a la premsa de Lleida (19171921) (2006); Jordi Manzanares Oliver: Alegría: una revista per combatre En Patufet (2007); Jaume Capdevila: L'Humor gràfic de Tísner: una aproximació a les caricatures d'Avel'lí Artís Gener, (2008).

32 Joan Manel Oller: Apunts per a una història de la premsa terrassenca, (Terrassa: Fundació Torre del Palau, 2002), Els Llibres de Terrassa. Terrassa viva; 5.

${ }^{33}$ Salvador Cargol: Fabricants de notícies: periodisme i canvi tecnològic a Girona, (Girona: Col-legi de Periodistes de Catalunya. Demarcació de Girona, 2006). Lluís Costa: Els mitjans de comunicació a Girona: (1787-2003); (Girona: Ajuntament de Girona i Institut d'Estudis Gironins, 2003).

${ }^{34}$ Miquel Codina i Genís i la col. de Josep M. Vivet i Falcó, Montserrat Teixidó i Florit: Retalls de premsa vigatana: 1803-2000, (Vic: Premsa d'Osona, 2000).

${ }^{35}$ Pere Anguera... [et al.]: Pensament $i$ literatura a Reus al segle XIX, (Reus: Edicions del Centre de Lectura, 2006); Joan Vernet Borràs: La Premsa a Reus durant el sexenni democràtic (1868-1874) [S.I., s.n., 2000]; Joan Navais, Pere Anguera [et al.]: La divulgació dels referents mítics a la premsa reusenca del primer catalanisme, (Reus: Edicions del Centre de Lectura, [2006] p. 303-316;

${ }^{36}$ Francesc Arcas, Carles Sàiz, Marc Vidal: La Premsa a Canet de Mar: (1885-2005), Canet de Mar: Edicions Els 2 Pins, 2004).

${ }^{37}$ Lluís Costa: Temps de transició: la premsa municipal al Baix Empordà, (Begur: Ajuntament de Begur, 2005).

${ }^{38}$ Carles Pont Sorribes i Jaume Guillamet Lloveras: Història de la premsa andorrana, 19172005; ([Andorra la Vella]: Govern d'Andorra, 2009).

${ }^{39}$ Guia de mitjans de comunicació en català, (Barcelona: APPEC, 2003). 


\subsection{Autors: memòria, obra pròpia i estudis}

Entre altres: Abdó Terrades ${ }^{40}$ per J. Guillamet, V. Almirall ${ }^{41}$ per diversos, J. Verdaguer $^{42}$ per diversos autors, F. Miquel i Badia ${ }^{43}$ per E. Casany i A. Tayadella, Mañé i Flaquer ${ }^{44}$ per M. Casas, Eugeni d'Ors ${ }^{45}$ per diversos curadors, Santiago Rusiñol ${ }^{46}$ per J. M. Cadena i per M. Casacuberta i V. Panyella, Josep M. Folch i Torres ${ }^{47}$ per Eulàlia Pérez Vallverdú, Joan Maragall i la Setmana Tràgica ${ }^{48}$ per I. Moreta, H. Raguer i J. C. García, Juan Luque ${ }^{49}$ per J. Cañellas, Josep M. Planes que amb J. Finestres ha reeditat o publicat antologies o reculls d'articles diversos ${ }^{50}$, Ramon Xuriguera ${ }^{51}$ per J. Camps, ${ }^{40}$ Jaume Guillamet: Abdón Terradas: primer dirigent republicà, periodista i alcalde de Figueres
per, Figueres: Institut d'Estudis Empordanesos, 2000
${ }^{41}$ Josep Pich: «L'evolució política i ideològica de Valentí Almirall i Llozer (1841-1904)», Afers,
44, Federalisme i catalanisme: Valentí Almirall (1841-1904) (Vic: Eumo, 2004); (2003) p. 31-51;
Josep M. Figueres: Valentí Almirall, forjador del catalanisme politic, (Barcelona: Generalitat de
Catalunya, 2004). Catalans il-lustres; 17, 2a ed. i de Valentí Almirall, Obra completa (1867-
1879), (Barcelona: Institut d'Estudis Catalans, 2009);
${ }^{42}$ Jacint Verdaguera: En defensa pròpia, (Barcelona: Tusquets, 2002), ed. a cura de N.
Garolera
${ }^{43}$ Enric Cassany i Antònia Tayadella: Francesc Miquel i Badia, crític literari al Diario de Barcelona (1866-1899), Barcelona: (Curial- Publicacions de l'Abadia de Montserrat, 2001).

${ }^{44}$ Montserrat Casas Nadal, Juan Mañé y Flaquer: crónicas de un viaje a Italia: 1862, (Lleida: Promociones Publicaciones Universitarias, 1997).

${ }^{45}$ EI Glosari d'Eugeni d' Ors... s'ha editat en diverses edicions corresponents a les publicades a La Veu de Catalunya Així: Glosari, 1908-1909; edició i presentació de Xavier Pla; amb col-laboració en l'anotació de Jordi Albertí; (Barcelona: Quaderns Crema, 2001). 1910-1911; 1912-1913-1914 en edició i presentació de Xavier Pla; anotació de Jordi Albertí, (Barcelona: Quaderns Crema, 2003) i Glosari 1915 en edició i presentació per Josep Murgades (Barcelona: Quaderns Crema, 1990).

${ }^{46}$ Josep M. Cadena se n'ha ocupat, entre altres amb un treball sobre el "Xarau» a L'Esquella a Treballs de Comunicació, (Barcelona: Institut d'Estudis Catalans) i "Santiago Rusiñol, col/laborador habitual de la premsa catalana del seu temps» al Butlletí de la Real Academia de Belles Arts de Sant Jordi, 20 (2006); Vinyet Panyella: Santiago Rusiñol, el caminant de la terra. (Barcelona: Edicions 62, 2003); Una selecció d'escrits a Santiago Rusiñol: Espurnes de la guerra. Deu jorns al front italià, (Barcelona: L'Avenç, 2004).

${ }^{47}$ Ultra la tesi doctoral, amb referències a l'activitat periodística ha tingut cura de l'aplec: Cavalcant l'ideal: articles de batalla de Josep M. Folch i Torres; (Valls: Cossetània, 2004), Memòria del segle XX; 3.

${ }^{48}$ Joan Maragall: La Setmana Tràgica. Tres articles, ed. d'Ignasi Moreta, (Barcelona: Fragmenta editorial, 2009) i La Setmana Tràgica: tres articles de Joan Maragall, ed. d'Hilari Raguer. (Barcelona: Claret, 2009). José Carlos García Rodríguez: ¿Arde Barcelona?: la Semana Trágica, la prensa y la caída de Maura, (Astorga: Akrón, 2010).

${ }^{49}$ Juan Cañellas Romero, Juan Luque corresponsal de Diario de Barcelona en Melilla: selección de crónicas (1921-1927), (Melilla: Consejería de Cultura, Servicio de Publicaciones, 2004); Juan Luque García, El desembarco de Alhucemas: crónicas periodísticas de Juan Luque, Diario de Barcelona, 1925, (Melilla: Consejería de Cultura. Servicio de Publicaciones, 2007) i De Tánger a La Meca: crónicas de viajes y exploraciones publicadas en la revista Algo, 19331935 (Melilla: Servicio de Publicaciones, Consejería de Cultura 2009)

${ }^{50}$ Josep M. Planes: Nits de Barcelona, (Barcelona: Proa, 2001), ed. facsímil de l'original de 1931. El 2003 la Llibreria Catalònia la reedità, en edició no venal facsímil per la qualitat de les il-lustracions d'Oleguer Junyet i la bellesa de la composició. En ambdós casos amb pròleg de 
Lluís Companys ${ }^{52}$ per J. M. Figueres, Andreu $\mathrm{Nin}^{53}$ per A. Benito, Domènec Guansé ${ }^{54}$ per F. Foguer i per Josep Bargalló ${ }^{55}$, Irene Polo ${ }^{56}$ per G. Santa Maria i M. Tur, Gaziel ${ }^{57}$ per M. Llanas i P. García Planas, Carles Sentís ${ }^{58}$ per J. Guillamon, Domènec de Bellmunt ${ }^{59}$ per Francesc Canosa, M. Serra i Moret ${ }^{60}$ per A. Mayayo i M. A. Velasco, Jaume Passarell ${ }^{61}$ per V. Soler, Joaquim Xirau ${ }^{62}$ per K. Moret, Josep M. Rendé ${ }^{63}$ per A. Gavaldà, Joan Oliver ${ }^{64}$ per C. Puig, Prat de la Riba ${ }^{65}$ per A. Balcells, J. M. Ainaud, J. M. Casasús i J. M. Nespereira, J. M. de Sagarra ${ }^{66}$ per N. Garolera,

Josep M. de Sagarra i colofó de Carles Soldevila. També Els gàngsters de Barcelona (Barcelona: Proa, 2002) i 1907-1936 Planes d'esport (Barcelona: Proa, 2007) ambdós amb introduccións de Finestres i la biografia: Josep M. Planes: set trets al periodisme de la Rabassada (Barcelona: Pòrtic, 2007).

${ }^{51}$ Josep Camps i Arbós: Ramon Xuriguera (1901-1966): biografia, activitat cultural i literatura (Barcelona: Publicacions de l'Abadia de Montserrat, 2007).

${ }^{52}$ Josep M. Figueres: Lluís Companys: diputat per Sabadell: periodisme, política i conflicte social, 1920-1925, (El Prat de Llobregat: Rúbrica, 2004).

${ }^{53}$ Andreu Nin: El Jove Andreu Nin: textos periodístics a cura d'Ernest Benito; [presentació: Víctor Alba].

${ }^{54}$ Domènec Guansé: La revolució cívica: articles de La Publicitat (1937-1939); edició a cura de Francesc Foguet i Boreu, (Valls: Cossetània, 2008), Memòria del segle XX; 13.

${ }^{55}$ Josep Bargalló: "Periodisme, crítica i biografia» a Domènec Guiansé. Revisió i actualitat, Tarragona: Arola, 2005, p. 87-104

${ }^{56}$ Glòria Santa Maria i Maria Tur: Irene Polo: La fascinació del periodisme. Cròniques (19301936), (Barcelona: Quaderns Crema, 2003).

${ }^{57}$ Manuel Llanas: «Índex de les col-laboracions de Gaziel a la premsa fins a 1938», (Barcelona: Societat Catalana de Llengua i Literatura, 2001); Agustí Calvet, Gaziel: En las trincheras, a cura de Plàcid García Planas (Barcelona: Diéresis, 2009).

${ }^{58}$ Carles Sentís: L'Instant abans del 36 (Barcelona: La Campana, 2004).

${ }^{59}$ Bellmunt, Domènec de, La Barcelona pecadora: els reportatges de l'Àngel bohemi; edició de Francesc Canosa (Barcelona: Acontravent, 2009).

60 Universitat de Barcelona. Centre d'Estudis Històrics Internacionals: Fons Manuel Serra i Moret: 1939-1963: cartes, articles de premsa i documents, edició, introducció i notes: Andreu Mayayo i Miquel Àngel Velasco (Catarroja: Afers; Barcelona: Centre d'Estudis Històrics Internacionals, 2006), Els Papers del Pavelló de la República; 3.

${ }^{61}$ Jaume Passarell: Bohemis, pistolers, anarquistes i altres ninots: (articles 1929-1940) edició a cura de Valentí Soler, (Barcelona: Acontravent, 2010).

${ }^{62}$ Kima Moret: «Textos de guerra i exili poc coneguts de Joaquim Xirau (1931-1941)» a El pensament de Joaquim Xirau (Girona: Documenta, 2007).

${ }^{63}$ Antoni Gavaldà: El batec periodístic d'un dirigent cooperativista català: Josep M. Rendé $i$ Ventosa: escrits 1903-1925, (Valls: Cossetània, 2007).

${ }^{64}$ Carme Puig Molist: Les col-laboracions de Joan Oliver al Diari de Sabadell: 1923-1928 (Barcelona: Publicacions de l'Abadia de Montserrat, 2001).

${ }^{65}$ Disposem de l'obra completa a cura d'Albert Balcells i Josep M. Ainaud de Lasarte, (Barcelona: Institut d'Estudis Catalans: Proa, 1998-2000 3 v. Monografies de la Secció Històrico-Arqueològica (Institut d'Estudis Catalans); Conté: Vol. 1. 1887-1898 - Vol. 2. 18981905 i Vol. 3. 1906-1917); de diversos estudis de Josep M. Casasús entre els que destaca la visió del seu periodisme (Castellterçol, Casa Museu Prat de la Riba) i de Manuel Pérez Nespereira, Manuel: Prat de la Riba i la "Revista Jurídica de Catalunya": la proposta de codis 
J. V. Foix ${ }^{67}$ per P. Gómez, Tomàs Garcés ${ }^{68}$ per V. Soler, Fages de Climent $^{69}$ per J. Guillamet, Josep $\mathrm{Pla}^{70}$ per X. Pericay, la família Manegat ${ }^{71}$ per L. I. Manegat, Nèstor Luján $^{72}$ per A. Pons, Joan Gols ${ }^{73}$ per diversos autors en el volum col-lectiu, Carles Esplà $^{74}$ per Angosto i per Puig, Just Cabot ${ }^{75}$ per V. Soler, Pere Calders ${ }^{76}$ per C. Puig, Josep Güell ${ }^{77}$ per C. Duran, Joaquim Ventalló ${ }^{78}$ per P. Vinyes, Vergés ${ }^{79}$ per J. C. Vergés, Indaleci Castells ${ }^{80}$ per J. Martí, Pere Aldavert ${ }^{81}$ per Carola Duran i Núria Florensa, Pere

jurídics de la indústria $i$ el dret de coalició obrera (Barcelona: II-lustre Col-legi d'Advocats de Barcelona: Acadèmia de Jurisprudència i Legislació, 2007), p. 957-966.

${ }^{66}$ Narcís Garolera ha editat de Josep M. de Sagarra: L'ànima de les coses. Articles a "La Publicitat" (1922-1929), (Barcelona: Quaderns Crema, 2001), El perfum dels dies. Articles a "Mirador" (1929-1936), (Barcelona: Quaderns Crema, 2004) i Cartas europeas. Crónicas en "El Sol" (1920-1928), de Sagarra i Josep Pla. (Barcelona: Destino, 2001) així com l'articulistica de Sagarra en la seva obra completa (València, Tres i Quatre, 1998 $\rightarrow$ ) especialment: Cafè, copa $i$ puro -vol. 9, i L'aperitiu (vols. 10 i 11).

${ }^{67}$ Pere Gómez i Inglada: Quinze anys de periodisme: les col/laboracions de J.V. Foix a La Publicitat (1922-1936), (Barcelona: Institut d'Estudis Catalans, 2010).

${ }^{68}$ Valentí Soler: Tomás Garcés: periodisme i crítica, (Barcelona: Publicacions de l'Abadia de Montserrat, 2010).

${ }^{69}$ Carles Fages de Climent: Articles; edició a cura de: Jaume Guillamet i Anna Teixidor, (Girona: Brau, 2003).

${ }^{70}$ Xavier Pericay: Josep Pla y el viejo periodismo, (Barcelona: Destino, 2009) Imago mundi; 161. També Cuatro historias de la República Julio Camba ... [et al.]; edició de Xavier Pericay (Barcelona: Destino, 2003) Imago mundi; 18. Conté: Madrid, el advenimiento de la República Josep Pla; prólogo de Xavier Pla. Los Enemigos de la República Manuel Chaves Nogales; prólogo de Andrés Trapiello. Haciendo República Julio Camba; prólogo de Arcadi Espada. La República sin republicanos.

${ }^{71}$ Luis Ignacio Manegat de Urmeneta: Los Manegat y su historia, edició privada, (Barcelona: Manuscrit Memory Press, 2006).

${ }^{72}$ Agustí Pons: Nèstor Luján: el periodisme liberal, (Barcelona: Columna: Fundació Catalunya Oberta, 2004).

${ }^{73}$ DD. AA.: Joan Gols i Soler: un personatge singular, (Tarragona: Arola, 2009).

${ }^{74}$ Pedro L. Angosto, Julia Puig (eds.): Carles Esplà, un periodista republicà: cròniques, conferències i correspondència amb Tarradellas, (València: Publicacions Universitat de València, 2007).

${ }^{75}$ Valentí Soler: El periodisme silenciat: Just Cabot: vida i cartes de l'exili (1939-1961), (Barcelona: A Contravent, 2008), Periodisme; 1.

${ }^{76}$ Carme Puig Molist: Pere Calders $i$ el seu temps, (Barcelona: Universitat Autònoma de Barcelona (Departament de Filologia catalana): Publicacions de l'Abadia de Montserrat, 2003), Biblioteca Milà i Fontanals; 43.

${ }^{77}$ Carola Duran i Tort: «Josep Güell i Mercader, cronista de La Renaixensa», (Reus: Arxiu Històric Municipal, 2007).

${ }^{78}$ Pau Vinyes i Roig: Visca la República!: Joaquim Ventalló, periodista, polític, poeta i traductor, (Barcelona: DUXELM i Fundació Josep Irla, 2010).

${ }^{79}$ Josep C, Vergés: Un País tan desgraciat: memòria compartida amb l'editor de Destino Josep Vergés; [introducció: Dolors Lamarca] [Barcelona]: Sd. edicions, 2007), La República Catalana; 1.

${ }^{80}$ Josep Martí i Baiget: Indaleci Castells Oller (1864-1930): una vida al servei de Valls (biografía política), (Valls: Cambra de Comerç de Valls: Cossetània, 2010). 
Mialet ${ }^{82}$ per Josep Martí, Aurora Bertrana ${ }^{83}$ per Neus Real, Ramon Barnils ${ }^{84}$ per C. Serrat, M. Vázquez Montalban ${ }^{85}$, X. Vinader ${ }^{86}$ per J. Busqué i Josep M. Huertas ${ }^{87}$ per J. Roglan. Pel que fa a l'articulisme polític de l'extensa nòmina esmentem Pere Macias ${ }^{88}$, J. A. González Casanova ${ }^{89}$, Joan Ferran ${ }^{90}$, Francesc Ferrer i Gironès ${ }^{91}$. No recollim ${ }^{92}$ la gran quantitat de llibres que procedeixen del periodisme i que poden ser tant de periodistes', com de polítics, etc.

Comencem a disposar de dades sobre els periodistes dels quals hom coneix la vida i l'obra. Tota una fornada de periodistes, escriptors i polítics que han escrit en premsa, amagats pel franquisme, segeixen essent recuperats. Es cerca la vida i l'obra i s'amplia la cerca de altres camps com la il-lustració, amb autors estudiats, entre altres, com Pellicer $^{93}$, Simont $^{94}$, Bagaria $^{95}$, Tísner $^{96}$, o amb visions de conjunt ${ }^{97}$.

\footnotetext{
${ }^{81}$ Núria Florensa i Soler, Pere Aldavert: l'home, el periodista i el polític catalanista; pròleg de Josep Fontana, (Barcelona: Publicacions de l'Abadia de Montserrat, 2007).

${ }^{82}$ Josep Martí i Baiget: Pere Mialet i Rabadà (1900-1968): periodista, narrador i comediògraf, (Valls: Institut d'Estudis Vallencs, 2005).

${ }^{83}$ Neus Real Mercadal: Aurora Bertrana, periodista dels anys vint $i$ trenta: selecció de textos (Girona: CCG Edicions: Fundació Valvi, 2007).

${ }^{84}$ Carles Serrat: Ramon Barnils. Articles, (La Magrana, Barcelona: 2002).

${ }^{85}$ Manuel Vázquez Montalbán, Obra periodística, ed. a cura de Francesc Salgado (Barcelona: Debate, 2010).

${ }^{86}$ Jaume Busqué i Barceló: Xavier Vinader i Sánchez: periodisme i compromís; pròleg: Antoni Segura i Mas (Catarroja: Afers; Barcelona: Centre d'Estudis Històrics Internacionals, 2009).

${ }^{87}$ Joaquim Roglan (cord.): Lliçons de periodisme de Josep M. Huertas Claveria, (Barcelona: Facultat de Comunicació Blanquerna, 2009), Trípodos (2009).

${ }^{88}$ Pere Macias i Arau: Des d'Olot per a Catalunya, (Olot: El Bassegoda, 2003).

${ }^{89} \mathrm{~J}$. A. González Casanova: Escrits de combat pel triomf de l'esquerra: 2001-2004, (Barcelona: Mediterrània: Fundació Rafael Campalans, 2005), Reflexió; 13.
}

${ }^{90}$ Joan Ferran: Els Pamflets d'en Ferran: recull d'articles polítics un xic grollers, àcids $i$ malintencionats Joan Ferran Barcelona: La Rosa de Barcelona, 2006.

${ }^{91}$ Francesc Ferrer i Gironès: un patriota al servei d'un poble coordinació i tria de textos: Miquel Torns, Pau Lanao, Carme Vinyoles, (Girona: Fundació Josep Irla: El Punt, 2005).

${ }^{92}$ Jaime Arias, Tal como los conocí: grandes protagonistas del cine, la política y la cultura en la libreta de un periodista Jaime Arias Barcelona: La Vanguardia, 2009.

${ }^{93}$ Jordi Artigas: «Josep Lluís Pellicer (1842-1901): corresponsal de guerra, antecessor dels repòrters fotogràfics actuals», (Barcelona: Societat Catalana de Comunicació, 2005), Treballs de Comunicació, (2005, setembre) 19, p. 67-87.

${ }^{94}$ Glòria d'Escala i Romeu: El dibuixant Josep Simont i Guillén (1875-1968), reporter gràfic de la I Guerra Mundial: un dibuixant d'actualitats a l'època de la naixent fotografia de reportatge, (Barcelona: Rafael Dalmau, 2002.

${ }^{95}$ Així catàlegs d'exposicions: Josep M. Cadena: Lluís Bagaria: caricaturista del món barceloni: llegat Maria Cladellas [coordinació: Pilar Vélez]; ([Sabadell]: Museu d'Art de Sabadell, 2003). De monografies: Emilio Marcos Villalón: Luis Bagaría entre el arte y la política, (Madrid: Biblioteca Nueva, 2004); Bagaría en El Sol: política y humor en la crisis de la Restauración, (Madrid: Fundación Mapfre, 2007); Lluís Bagaria: La guerra no fa riure: caricatures antifeixistes a La Vanguardia (1936-1938); selecció, introducció i comentaris: Jaume Capdevila, (Barcelona: 
o s'han recollit sèries d'articles com en els casos de Josep M. Folch i Torres ${ }^{98}$ o Quim Monzó ${ }^{99}$. També les antologies d'obra periodística han estat editades així B. Porcel ${ }^{100}$, Josep Pernau ${ }^{101}$.

En molts d'aquets casos els mateixos estudiosos han tingut cura de biografies o altres treballs que no anotem en ser editats amb anterioditat al 2000. En memòries de Joan Vinyas i Comas ${ }^{102}$, de les originals de F. González Ledesma ${ }^{103}$, Carles Sentís ${ }^{104}$, Blas Guimerà $^{105}$, Jaume Castell ${ }^{106}$, Jaume Gascón ${ }^{107}$, Agustí Pons ${ }^{108}$, R. Font ${ }^{109}$ també de

Duxelm, 2007); La caricatura social y política: Hogarth, Grosz, Bagaria... [et al.] [València]: Pentagraf, 2007); José Esteban: Caricaturas republicanas Luis Bagaría; ([Madrid]: Rey Lear, 2009).

${ }^{96}$ Jaume Capdevila: L'humor gràfic de Tísner. Una aproximació a les caricatures d'Avel.li Artís Gener, (Lleida, Pagès, 2009).

${ }^{97} J o s e p$ M. Cadena (coord.): 25 años de humor en "El Periódico de Catalunya" (Barcelona: El Periódico de Catalunya, 2003); Anna Busto Bonvehí, Marc Macià Farré i Margarida Sabaté Vergé: L'Humor gràfic a la premsa de Lleida, 1883-1975, [Lleida]: IMAC: Pagès, 2005, Banqueta: quaderns de divulgació ciutadana, 33); Lluís Solà i Dachs: La caricatura política $i$ social a Catalunya (1865-2005), [Barcelona]: Duxelm, 2005) i Papitu (1908-1937) i les publicacions eroticosicalíptiques del seu temps, (Barcelona: Dux, 2008), Duxartis, 4. Com a monografies personals les de García Guatas, Manuel: "La daricatura en la prensa antes y después de una guerra: Manolo del Arco 1909-1971», Artigrama, 15, [Zaragoza: Departamento de Historia del Arte, 2000] p. 461-481).

${ }^{98}$ L'edició de les Pàgines viscudes de Josep M. Folch i Torres compta amb els volums: El Llibant del pou (Palau-Solità i Plegamans]: Fundació Folch i Torres, 2000); Pàgines viscudes del temps de la guerra, (Palau de Plegamans: Ramón Folch i Camarasa, 2000); La veu dels àngels (Palau-Solità i Plegamans: Fundació Folch i Torres, 2000); 1915 (Palau-Solità i Plegamans: Fundació Folch i Torres, 2006) i 1916 (Palau-Solità i Plegamans: Fundació Folch i Torres, 2008).

${ }^{99}$ Hotel intercontinental (1991); No plantaré cap arbre (1995); El tema del tema (2003); Catorze ciutats comptant-hi Brooklyn (2004) i Esplendor i glòrica de la Internacional Papanates, (Barcelona: Quaderns Crema, 2010).

${ }^{100}$ Porcel periodista. Sus mejores columnas en La Vanguardia, (Barcelona: Libros de Vanguardia, 2009).

${ }^{101}$ Josep Pernau: La democràcia com a norma en l'exercici del periodisme: recull d'articles (1954-2002), (Barcelona]: Diputació de Barcelona: Col-legi de Periodistes de Catalunya, 2002) Vaixells de paper; 29.

${ }^{102}$ Lluís Costa: Memòries d'un gironí. Una visió de la premsa de Girona, amb estudi introductori de, Girona, Col-legi de Periodistes de Catalunya. 2000).

${ }^{103}$ Francisco González Ledesma: Historia de mis calles, (Barcelona: Planeta, 2006).

${ }^{104}$ Carles Sentís: Memòries d'un espectador, 1911-1950, amb la col-laboració de Xavi Ayén (Barcelona: La Campana, 2006).

${ }^{105}$ Blas Guimerá Altabás: La meva aventura en la premsa local: (un capítol de la moderna $i$ invisible Inquisició), (Tortosa: ed. d' autor, 2006).

${ }^{106}$ Jaume Castell i Abella: Records per garbellar; pròleg de Francesc Sanuy, (Maçaners: Abadia, 2005).

${ }^{107}$ Jaume Gascon i Rodà: Memòries d'un periodista català (1904-1940), (Olot: Ajuntament d'Olot, Institut de Cultura de la Ciutat d'Olot, 2006), 2 vol.

${ }^{108}$ Agustí Pons: Temps indòcils a Catalunya, (Barcelona: Angle, 2007). 
recopilacions d'entrevistes com les de W. Espina ${ }^{110} \mathrm{i}$ d'alguna reedició com les de Xammar en format diàleg ${ }^{111} i$ obres d'homenatge com la d'Eugeni Molero ${ }^{112}$. A fegim treballs d'autors en conjunt com els d'Elvira Altés ${ }^{113}$, Quim Torra ${ }^{114}$ i Just Arévalo $^{115} \mathrm{i}$ narrativa amb to autobiogràfic com la de Puig i Ferreter en constant reedició $^{116}$.

\subsection{Estudis sobre diaris i revistes}

Pel que fa a diaris la relació de treballs no és massa extensa. Disposem de treballs sobre el Diari Catala ${ }^{117}$ per J. Pich i sobre La Renaixensa ${ }^{118}$ de Carola Duran i Tort que ha ha estudiat impremta, revista i diari. De La Veu de Catalunya ${ }^{119}$, de Treball $^{120}$ i, l'extensa monografia de LI. Costa sobre L'Autonomista ${ }^{121}$ gironí. De diaris més moderns destaquem Segre ${ }^{122}$ com a obra feta pel periòdic i de conjunt. En relació a $L a$

${ }^{109}$ Ricard Font Sugranyes: Ni callar ni aplaudir: vint anys de periodisme crític a l'Alt Pirineu
(1969-1989); pròleg: Margarita Rivière Lleida: Pagès, 1995).
${ }^{110}$ Converses amb Wifredo Espina: cinc entrevistes entre 1968-2003, a cura de Josep Maria
Espina-Pahí; Elisenda Carbonell ... [et al.]; pròleg de Llorenç Gomis.
${ }^{111}$ Seixanta anys d'anar pel món: converses amb Josep Badia i Moret d'Eugeni Xammar, (Barcelona: Quaderns Crema, 2007). L'ou de la serp (Barcelona: Quaderns Crema, 1900) i Quim Torra i Pla: Periodisme? Permetin!: la vida i els articles d'Eugeni Xammar; pròleg d'Enric Vila, (Barcelona: Símbol, 2008).

${ }^{112}$ Eugeni Molero: periodista, escriptor i sardanista: Barcelona, 1943-Sant Pere de Ribes, 1984; (Vilanova i la Geltrú: Consell Comarcal del Garraf: Arxiu Comarcal del Garraf, 2008).

${ }^{113}$ Elvira Altés: Les Periodistes del temps de la República, Barcelona: Col.legi de Periodistes de Catalunya: Diputació de Barcelona: 2007, Vaixells de paper; 32

${ }^{114}$ Torra, Quim, Viatge involuntari a la catalunay impossible: tres periodistes oblidats i l'espectre d'Eugeni Xammar, (Barcelona : Proa, 2010).

${ }^{115}$ Just Arévalo: La cultura de masses a la Barcelona del nou-cents, (Barcelona: Publicacions de l'Abadia de Montserrat, 2002).

${ }^{116}$ Joan Puig i Ferreter: Servitud, (Barcelona: Proa, 2002). Nova edició.

${ }^{117}$ Josep Pich i Mitjana amb Almirall i el Diari Català (1879-1881): I'inici del projecte politicoideològic del catalanisme progressista; pròleg de Josep Fontana, Barcelona: Institut Universitari d'Història Jaume Vicens i Vives; Vic: Eumo, 2003.

${ }^{118}$ Pere Aldavert $i$ "La Renaixensa", veus discordants de la premsa barcelonina dels noranta, (Barcelona: Publicacions de l'Abadia de Montserrat, 2000); La Renaixensa, primera empresa editorial catalana, (Barcelona: Publicacions de l'Abadia de Montserrat, 2001).

${ }^{119}$ Josep M. Figueres: «Prensa y política en la II República: el epistolario de F. Cambó a Lluís Duran i Ventosa sobre La Veu de Catalunya (1931-1932) [Alessandria: Edizioni dell'Orso], 2001-2002 a Spagna contemporanea, 19 (2001) i 21 (2002).

${ }^{120}$ Treball: 1936-2006: [diari dels treballadors de la ciutat i el camp], Barcelona: Fundació Nous Horitzons, 2006.

${ }^{121}$ Lluís Costa: El Autonomista: el diari dels Rahola: els orígens del periodisme modern a Girona: 1898-1939, Girona: Col·legi de Periodistes de Catalunya. Demarcació de Girona, 2000. 
Vanguardia $^{123}$, el periòdic de la família Godó, el portavions de la premsa barcelonina disposem de tres treballs de Josep M. Huertas. Anna Nogué i C. Barrera i M. Carol. Del diari El Periódico ${ }^{124}$ esmentem una obra d'aniversari editada pel diari. D'altres diaris amb impacte a Catalunya ha estat el tancament irregular del periòdic basc Egunkaria vist com atemptat a la llibertat d'expressió i la resposta a Catalunya fou molt contundent, amnb actes, crítiques i llibres ${ }^{125}$.

De les publicacions disposem d'un ric apartat amb bibliografia específica i fins i tot de sèries de textos sintètics com els elaborats per Jordi Albertí a Revista de Catalunya on ha publicat al llarg la segona meitat de la primera dècada d'aquest segle gairebé una vintena de monografies de significatives revistes en la història del periodisme, s'ha ocupat així de: Universitat Catalana (1900-1902); Auba (1901-1902); Palla Nova (1904); Art Jove (1905); Garba (1905-1906); Occitània (1905); Catalònia (1906); Jove Catalunya (1906-1907); El Gràfic (1908); Revista Catalana (1909-1910); Ciutat (19101911); Picarol (1912); Cultura (1914); Els Amics d'Europa (1915-1919); La mà trencada (1924-1925); Quart Creixent (1957-1958), etc.. La revista consultable com totes les científiques importants a RACO disposa d'índexs a través dels quals podem accedir fàcilment al seu contingut.

Sobre indexacions disposem de Carles Albesa: Excursionisme (1928-1931). Un periodic més enllà de l'excursionisme, (Barcelona: Publicacions de l'Abadia de Montserrat, 2003). En versió digital, de Teresa Férriz, deu revistes d'exili en edició a la UOC un dels primers títols sobre història del periodisme en versió electrònica: Escriptors i revistes catalanes a l'exili, (Barcelona, UOC, 2009).

De títols concrets encetem amb Destino del qual han aparegut diverses aportacions: Alexandre Porcel: La Crónica de Destino, (Barcelona: Destino, 2003 a Imago mundi, 38); de Queralt Solé Barjau El "Destino" de Burgos [Catarroja]: Afers, [2004] p. 213-219 a Sense memòria no hi ha futur: actes de les III Jornades de Joves Historiadors i Historiadores. També: Isabel de Cabo: La Resistencia cultural bajo el franquismo: en

\footnotetext{
122 Segre: [Lleida]: Prensa Leridana, 2002.

${ }^{123}$ Tots del mateix 2006 o sigui 125 anys després del naixement són l'assaig: Josep M. Huertas Una Història de "La Vanguardia" (Barcelona: Angle Editorial, 2006) on amplia un article de L'Avenç sobre els directors del mateix diari i la tesi doctoral d' Anna Nogué dirigida per Carlos Barrera signant els dos el treball: La Vanguardia, del franquismo a la democracia, (Madrid: Fragua, 2006). També el catàleg de l'exposició sobre el diari que va comissariar Màrius Carol: El Pols dels dies: 125 anys de La Vanguardia, Barcelona: Centre de Cultura Contemporània de Barcelona, 2006.

${ }^{124} 30$ anys el Periódico: 1978-2008, en doble edició, com el diari, en català i en castellà, ([Barcelona]: El Periódico, [2008]).

${ }^{125}$ Egunkaria endavant: tots $i$ totes som Egunkaria, Gràcia [Barcelona]; Bages: Plataforma per Egunkaria, 2003 i, especialment, d'Alfredo Díaz i Sergio Arévalo: Plouen mentides: crònica del tancament d'Egunkaria Lorea Agirre, DVD, inclou: El tancament d'Egunkaria: reaccions a Catalunya, (Barcelona: Plataforma per Egunkaria, 2005).
} 
torno a la revista Destino, 1957-1961, pròleg de Jordi Casassas, (Barcelona: Áltera, 2001).

Del conjunt de publicacions esmentem de Núria Codina Solà: 30 anys amb les nostres cooperatives: revista Cooperació Catalana (Barcelona: Fundació Roca i Galés: ECOS, 2010) de Silvia Caballeria i M. Carme Codina: Aproximació a "Oriflama": una revista catalana sota el franquisme, (Barcelona: Publicacions Col-legi de Sant Miquel dels Sants: Editorialdiac, 2005). De la notable quantitat de monografies sobre publicacions esmentem monogràfies sobre Occitània ${ }^{126}$, Revista Blanca ${ }^{127}$, En Patufet ${ }^{128}$, El Nuvol Negre $^{129}$, Studium $^{130}$, El Europeo $^{131}$, Serra d'Or $^{132}$, Endavant $^{133}$, Alegria $^{134}$, Geminis $^{135}$, $L^{\prime}$ Hora de Catalunya ${ }^{136}$...

\footnotetext{
${ }^{126}$ Montserrat Corretger: La revista Occitània (1905) i l'epistolari dels seus directors, Josep Aladern i Pròsper Estieu (1903-1913): baula en la contrucció de la identitat catalanooccitana, (Valls: Cossetània, 2004) a Literatura i identitats, Magí Sunyer, Roser Pujadas i Pere Poy (eds). ${ }^{127}$ Javier del Valle-Inclán: Biografía de La Revista Blanca: 1898-1905, (Barcelona: Sintra, 2008).

${ }^{128}$ Tenim les actes d'una jornada dedicada a una revista, fou la de més alt tiratge en la història del segle XX i, efectivament, En Patufet fou estudiada per una desena d'especialistes des de diversos angles a En Patufet, cent anys: la revista $i$ el seu impacte: simposi celebrat a l'Aula Magna de la Universitat de Barcelona el dia 11 de març de 2004 edició i presentació: Jordi Castellanos, (Barcelona: Abadia de Montserrat: Departament de Filologia Catalana i Departament de Periodisme i Ciències de la Comunicació de la Universitat [Autònoma] de Barcelona, 2004).
}

${ }^{129}$ Albert Mas i Pimàs: El Núvol Negre: 1932-1933, Tordera: Ajuntament de Tordera, 2000.

${ }^{130}$ Jaume Guillamet, Joan Ferrerós, Rafel Pascuet: Studium, la revista del jove Dalí, (Figueres: Brau, 2003).

${ }^{131}$ Paula A. Sprague, El Europeo, Barcelona, 1823-1824: prensa, modernidad y universalismo Madrid: Iberoamericana; Frankfurt am Main: Vervuert, 20091 v. (364, 408, 399, 138 p.); Inclou facsímil: El Europeo: periódico de ciencias, artes y literatura.

${ }^{132}$ Carme Ferré Pavia: Intel-lectualitat i cultura resistents: Serra d'Or, 1959-1977 (Cabrera de Mar: Galerada, 2).

${ }^{133}$ Endavant: òrgan del Moviment Socialista de Catalunya: federació democràcia, socialisme (1945-1968); (Barcelona: Fundació Rafael Campalans, 2006).

${ }^{134}$ Jordi Manzanares: Alegria una revista per combatre El Patufet. (Lleida, Pagès, 2007), col. Retalls.

${ }^{135}$ Revista Geminis (Tarragona, Diputació de Tarragona, 2005) [Revista de Tortosa del 1952 al 1961], Edició facsímil.

${ }^{136}$ Josep M. Figueres: «Inventaris i catàlegs: "L'Hora de Catalunya": diari català clandestí irrecuperable o l'hemerografia com a eina de referència de la consciència nacional», Revista de Catalunya, (2001). 


\title{
1.4 Altres estudis
}

Aquest decenni ha contemplat el naixement d'unes plataformes expositives cridades a projectar la bibliografia de forma notable més enllà de les revistes sobre la matèria procedents de les universitats com Anàlisi (UAB) o Trípodos $^{137}$ (URL) i de I'IEC: Periodística i Treballs de Comunicació. Cal sumar-hi en format digital ${ }^{138}$ Gazeta I'IEC i Obra Periodística (UPF). Dues universitats públiques, UAB i UPF, tenen cura de les jornades bianuals d'història de la premsa ${ }^{139}$ amb la col·laboració de la Generalitat de

\begin{abstract}
${ }^{137}$ D'aquesta esmentem 20 el número monogràfic Els clàssics del periodisme català de la Renaixença a la Guerra Civil (2007) amb Carles Geli: «Entre somriure i plors: apunts per a un context de la premsa catalana (1890-1936)»; Ferran Toutain: «Un món de mones. La persistència de Robert Robert»; Miquel Tresserras: «Pedagogia i ciutat en el "Glosari" de Xènius»; Xavier Pla: «Eugeni d'Ors i el periodisme d'idees»; Enric Vila: «Josep Pla, periodisme i patriotisme»; Ferran Sáez Mateu: «El Montaigne de Pla: del "moralisme" clàssic al periodisme modern»; Narcís Garolera: «L'articulisme literari de Josep M. de Sagarra»; Francesc Canosa: «Eugeni Xammar: un superperiodista sobrevolant el futur»; Núria Santamaria: «Carles Soldevila, periodista»; Francesc-Marc Alvaro: «Influència i compromís en Gaziel»; Josep M. Casasús: "Gaziel en el canon i en la tradició d'escola»; Jordi Finestres: «Josep M. Planes, el reporter calidoscòpic»; Sergi Dòria: «Els cent vuitanta dies de Josep M. Planes a Imatges» i Antoni Aira: «Entrevista amb Carles Sentís, un periodista entre dos segles».
\end{abstract}

${ }^{138} \mathrm{El}$ n. 2 conté les actes de la Jornada d'Història la Premsa d'Esquerra Republicana de Catalunya, 1931-1975 (2009: Barcelona, Catalunya). La Premsa d'Esquerra Republicana de Catalunya, 1931-1975: Barcelona, 30 octubre 2009, Museu d'Història de Catalunya [Barcelona]: Fundació Josep Irla: Generalitat de Catalunya, Memorial Democràtic; [Bellaterra]: Universitat Autònoma de Barcelona, [2009] (19 fasc.); A més de l'edició policopiada pels assistents, conservada en alguna biblioteca es pot consultar al web de l'IEC en el contingut: "La premsa i ERC (1931-1939) i l'exili» per Josep M. Cadena; «Els periodistes d'Esquerra» per Josep M. Casasús i Guri; «La premsa com a mirall i projecció d'una força política: ERC, 1931-1939» per Albert Balcells; "La premsa d'ERC a Badalona (1931-1936)» per Jordi Albadalejo i Blanco; «Lluita, setmanari d'ERC a Vic (1932-1933)» per Imma Albó i Vidal de Llobatera; «Imatges de paper: els diaris d'ERC i el projecte de televisió pública catalana a la República» per Francesc Canosa; «Dibuixant amb l'Esquerra. Els ninotaires de la premsa d'ERC durant la República» per Jaume Capdevila; «Josep Claret, combat per la Nova arquitectura» Gemma Domènech Casadevall, per Rosa Maria Gil Tort; «Lluís Capdevila, corresponsal de guerra. Les cròniques al front d'Aragó (1936-1938)» per Josep M. Figueres; "La Batalla de l'Ebre: una visió des del diari La Humanitat» per José Miguel Hernández López; «Julià Gual (1905-1964), periodista i escriptor de combat» per Josep Puig i Pla; «L'activitat periodística i literària d'Antònia Abelló i Filella, a les publicacions republicanes entre 1932 i 1939» per Carme Puyol Torres; «Capçaleres d'ERC al Penedès republicà, reflex de les problemàtiques socials de la comarca vitivinícola» per Jaume Recasens i Bel; «Acció Ciutadana, Girona 1932-1934. Un setmanari de partit, model de premsa comarcal» per Carles Ribera Rustullet; «República: la premsa republicana a la Segarra» Jordi Soldevila i Roig; "D'El Pueblo a El Poble» per Josep Subirats Piñana; «Els butlletins de la secció departamental d'ERC del Sena (París): JEREC-ERC, Som, Butlletí d'ERC de París i Tribuna» per Robert Surroca i Tallaferro; "Empordà Federal i Josep Puig Pujades: expressió i guiatge d'un projecte periodístic i polític» per Anna Teixidor Colomer; «L'Empordà Republicà, 1978-1979: la difícil construcció d'una esquerra nacional durant la transició» per Albert Testart i Guri; «Joaquim Ventalló i Vergés en la seva etapa com a director de L'Opinió» per Pau Vinyes i Roig.

${ }^{139}$ Jornades d'Història de la Premsa (2es: 2007: Barcelona), Poder polític i resistència periodística: actes de les Segones Jornades d'Història de la Premsa edició a cura de Josep M. Figueres [Barcelona]: Generalitat de Catalunya, 2009, Lexikon papers; 4. El contingut dedicat a premsa catalana o feta a Catalunya és: Jaume Guillamet: «La teoria del quart poder. La funció política de la premsa segons el diari El Vapor (1833-38)»; Jordi Llimargas: "La Junta de la Província de 1794-1795, comunicació i poder polític a la Catalunya a finals de l'Antic Règim»; Javier Diaz Noci: «La premsa en basc i Catalunya: models periodístics i polítics (1800-1939)»; 
Catalunya les actes deles quals penja al web de la seva llibreria en accés obert, així (www.llibreriageneralitat.cat pot consultar-se Poder polític ir esistència periodística. Actes de les Segones Jornades d'Història de la Premsa (2009). Aquestes noves tribunes que ens acostaran a la recerca amb notable quantitat de treballs. Per la dècada que ens ocupa disposem de monografies sobre la premsa local i comarcal que hem citat per ciutats $\mathrm{i} o$ en conjunt agrupant els treballs en formats temàtics: premsa local $\mathrm{i}$ comarcal ${ }^{140}$ com abans hem vist col-leccions o revistes.

Pel que fa a estudis diversos de conjunt tenim treballs de Jaume Guillamet ${ }^{141}$, Josep M. Figueres $^{142}$ i Carme Ferré ${ }^{143}$ així com els apartats específics catalans a l'exposició sobre periodisme espanyol ${ }^{144}$. Corresponents al segle XIX, a més dels autors, diaris, etc. anteriors trobem treballs de J. Guillamet ${ }^{145} \mathrm{i}$ del carlisme ${ }^{146}$. Del primer terç del segle

Jordi Ibarz: «Mirant cap a una altra banda. La representació gràfica del treball a La Vanguardia durant els temps de la Primera Guerra Mundial, 1914-1919»; Alfons Gonzàlez Quesada: "Què llegien els nostres voluntaris a la Gran Guerra»; Anna Teixidor Colomer: «Set anys de Madame censura: La repressió de la premsa figuerenca durant la dictadura primoriverista (1923-30)»; Ferran Aisa: "Solidaridad Obrera, centenari d'un periòdic anarcosindicalista (1907-2007)»; Josep M. Casasús: «Quan l'Estat es va imposar brutalment sobre la premsa»; Xavier Ferré Trill: «Foment i el catalanisme republicà en una conjuntura definitòria: 1906-1910»; José M. Perceval i Carles Figuerola: «La visió de l'altre a la premsa infantil durant la Guerra Civil: entreteniment i propaganda», Francesc Canosa Farran: «La batalla per la realitat. La lluita a la premsa per uns mitjans audiovisuals catalans durant la República»; Jaume Recasens i Bel: «Fructidor, símbol de la resistència periodística al Penedès el primer terç del segle $X X_{\Perp}$; Josep M. Figueres: «Entre la informació i la propaganda. Premsa en la guerra civil espanyola (1936-1939)»; Carme Ferré Pavia: «Resistència cultural i exercici polític. Serra d'Or i l'entrenament per construir el país»; José M. Murià: «El Butlletí de Guadalajara: vint anys de catalanisme»; Francesc Salgado: "Siglo 20, un setmanari d'esquerres sota el franquisme. Vázquez Montalbán, redactor en cap i analista de política internacional»; Marcela Lucci: "La revista Ressorgiment a la Història catalana: la difusió dels ideals catalanistes a Buenos Aires durant les primeres dècades del segle XX»; Kima Moret: «Joaquim Xirau a la premsa de guerra i de l'exili (1939-1953)».

${ }^{140}$ Els Reptes de la premsa local i comarcal al segle XXI: actes del V Congrés de l'Associació Catalana de la Premsa Comarcal, (Valls: Cossetània, 2001); Associació Catalana de la Premsa Gratuïta, 1997-2007: ACPG 10 anys: la força d'un gran mitjà [Barcelona]: ACPG, 2007 ([Sant Adrià]: [IMGESA]); Llibre blanc 2010 de la premsa comarcal [Recurs electrònic]: premsa comarcal i local catalana d'informació general i amb difusió de pagament Barcelona: Fundació Catalana de la Premsa Comarcal i Local, 2010, 1 disc òptic (CD-ROM): Departament de Cultura i Mitjans de Comunicació.

${ }^{141}$ Jaume Guillamet: Las élites catalanas y la prensa: editores y directores, Casa de Velázquez: Maison des Pays Ibériques: Université de Provence, [2002] Collection de la Casa de Velázquez; 71.

${ }^{142}$ Josep M. Figueres: Premsa i nacionalisme: el periodisme en la reconstrucció de la identitat catalana, pròleg de Josep Faulí; epílegs d'Andreu Mas i Joan Pons (Barcelona: Pòrtic, 2002) i també Periodisme en la guerra civil (1936-39), (Barcelona: Publicacions de l'Abadia de Montserrat, 2010), Biblioteca Serra d'Or, 431.

${ }^{143}$ Carme Ferré Pavia (coord.): Un país de revistes: història dels magazins en català, (Barcelona: APPEC, 2009).

\footnotetext{
${ }^{144}$ Periodisme i periodistes: de les gasetes a la xarxa, (Barcelona: España Nuevo Milenio, 2001).

145 Jaume Guillamet: L'arrencada del periodisme liberal: política, mercat i llengua a la premsa catalana (1833-1874), (Vic: Eumo, 2010).
} 
XX esmentem diverses monografies ${ }^{147}$. Per la guerra civil treballs de Josep $M$. Figueres $^{148} \mathrm{i}$ en el marc del franquisme de F. Vilanova ${ }^{149}$. Més abundosos són els estudis per la transició amb aportacions de Josep M. Huertas ${ }^{150}$ i obres col-lectives ${ }^{151}$.

Pel moment present treballs sobre l'àmbit digital de V. Partal ${ }^{152}$ i R. Franquet ${ }^{153}$. Aspectes crítics i polèmics també són avaluats en dimensió històrica ${ }^{154} \mathrm{i}$ tanquem amb aspectes històrics de projecció internacional del periodisme.

${ }^{146}$ Seminari d'Història del Carlisme (6è: 2002: Solsona) Carlisme, foralisme i qüestió nacional: la premsa carlina: VI Seminari d'Història del Carlisme Solsona: Fundació Pública Comarcal Francesc Ribalta, 2002

${ }^{147}$ Francesc Santolària Torres: El banquet de la Victòria i els fets de ¡Cu-Cut!: cent anys de l'esclat catalanista de 1905, (Barcelona: Meteora, 2005); Carles Bastons i Vivanco: Unamuno: sus colaboraciones y su recepción en la prensa de Cataluña y... (algo en la de Mallorca), (Salamanca: Ediciones Universidad, 2003) a Miguel de Unamuno: estudio sobre su obra, 2003; Julia Cabaleiro Manzanedo: Paraules de dones en la premsa comarcal: primer terç del segle XX, (Sant Feliu de Llobregat: I' Ajuntament, 2002); Sonia del Río Santos: Corporativismo y relaciones laborales en Cataluña (1928-1929): una aproximación desde la prensa obrera (Bellaterra: Universitat Autònoma de Barcelona, 2002); Lluís Bonet i Armengol: La Mort de Gaudí i el seu ressò a la revista "El Propagador de la Devoción a San José", Barcelona: Claret, 2001; Carme Riera: La Recepció del Tercer Centenari d'El Quixot a la premsa de Barcelona (1905) (Barcelona: Reial Acàdemia de Bones Lletres de Barcelona, 2002).

${ }^{148}$ Josep M. Figueres: Periodisme en la guerra civil (1936-39), (Barcelona: Publicacions de l'Abadia de Montserrat, 2010), Biblioteca Serra d'Or, 431.

${ }^{149}$ Vilanova, Francesc: Una burgesia sense ànima: el franquisme i la traïció catalana Francesc Vilanova, (Barcelona: Empúries, 2010).

${ }^{150}$ Josep M. Huertas: El plat de llenties: periodisme i transició a Catalunya (1975-1985) [pròleg: Andreu Mayayo] Barcelona: Col-legi de Periodistes de Catalunya: Diputació de Barcelona, 2005.

${ }^{151}$ Memòria de la transició a Espanya i a Catalunya. 5, Els mitjans de comunicació Rafael Aracil, Andreu Mayayo, Antoni Segura (editors); s: Carme Alcalde ... [et al.]

Barcelona: Publicacions i Edicions de la Universitat de Barcelona, 2004. Ponències presentades al cinquè Curs Memòria de la Transició a Espanya i a Catalunya celebrat a la seu del Centre d'Estudis Històrics Internacionals (CEHI) i també: Francesc-Marc Álvaro... [et al.]; Joaquim Noguero (coord.) Embolicats amb el periodisme: reptes dels mitjans de comunicació catalans (1975-2006) Vilanova i la Geltrú: El Cep i la Nansa, 2007).

${ }^{152}$ Vicent Partal: Periodisme quàntic: fent periodisme a Internet: l'experiència dels primers deu anys de VilaWeb, (Palma: Edicions UIB, 2007).

${ }^{153}$ Rosa Franquet i Calvet: Assalt a la xarxa: la batalla decisiva dels mitjans de comunicació online en català, (Barcelona: Col-legi de Periodistes de Catalunya, 2006).

${ }^{154}$ Alfredo Marhuenda i Alfredo Fluixà: Agafa la lupa!: el sud als diaris, (Barcelona: Justícia i Pau, 2006), Cristianisme i Jústicia; 139 i Josep Huguet: Cornuts i pagar el beure: el discurs anticatalà a la premsa española Josep Huguet; antologia a cura de Rosa M. Cassà; pròleg de Salvador Cardús, 2a ed. (Barcelona: Columna, 2000). 